\title{
ON GRANULARITY
}

Poets extol the mirror-like surface of a still forest pond, the clarity of a gemstone, and the inexorably uniform flow of time. An uncritical analysis would have us believe that smooth and continuous are tantamount to beautiful. Anthropomorphic mapping of the concept onto human personality traits and appearance confirms the positive implications of smooth, uninterrupted, predicable continuity and consistency. Conversely, rough and coarse equate to unattractive stubble and sackcloth, jolting unpaved roads, and abrasive and barbaric people. ${ }^{1}$ According to Milton,2 "it is for homely features to keep home-/They had their name thence; coarse complexions/And cheeks of sorry grain will serve to ply/Thy sampler, and to tease the huswife's wool." The superficial association of good with continuous and bad with discontinuous does not, however, withstand careful scrutiny. Granularity is the essence of all that is beautiful and interesting.

The physical universe epitomizes granularity. From our own tiny blue granule we are awestruck by the pieces of the cosmos we can see, especially by the clump of granules we call the Milky Way. At the other extreme of scale, our subatomic constituents are becoming ever more granular. Even quarks may now be divulging their substructure. ${ }^{3}$ And at the intermediate scale of the sand pile, physicists are recognizing the unique properties of granular materials and how generalization of their behavior may explain physical phenomena far afield.4 Since the tendency on agitation of their container for large grains to rise while small grains fall analogizes well with machinations inside large organizations, we see even broader generalizations.

The role of human perception is perhaps the most fascinating aspect. Clearly, both in the physical universe and the anthropomorphic regime, the viewing distance matters. What or who seems smooth from afar may reveal grains and domains on closer inspection. Then these jagged irregularities may manifest exquisite uniformity from a still closer subgrain perspective. "To see a world in a grain of sand/And heaven in a wild flower,/Hold infinity in the palm of your hand/And eternity in an hour." 5

Granularity plays a crucial role in the digital age (the digits themselves epitomize the grains). In numerical analysis,

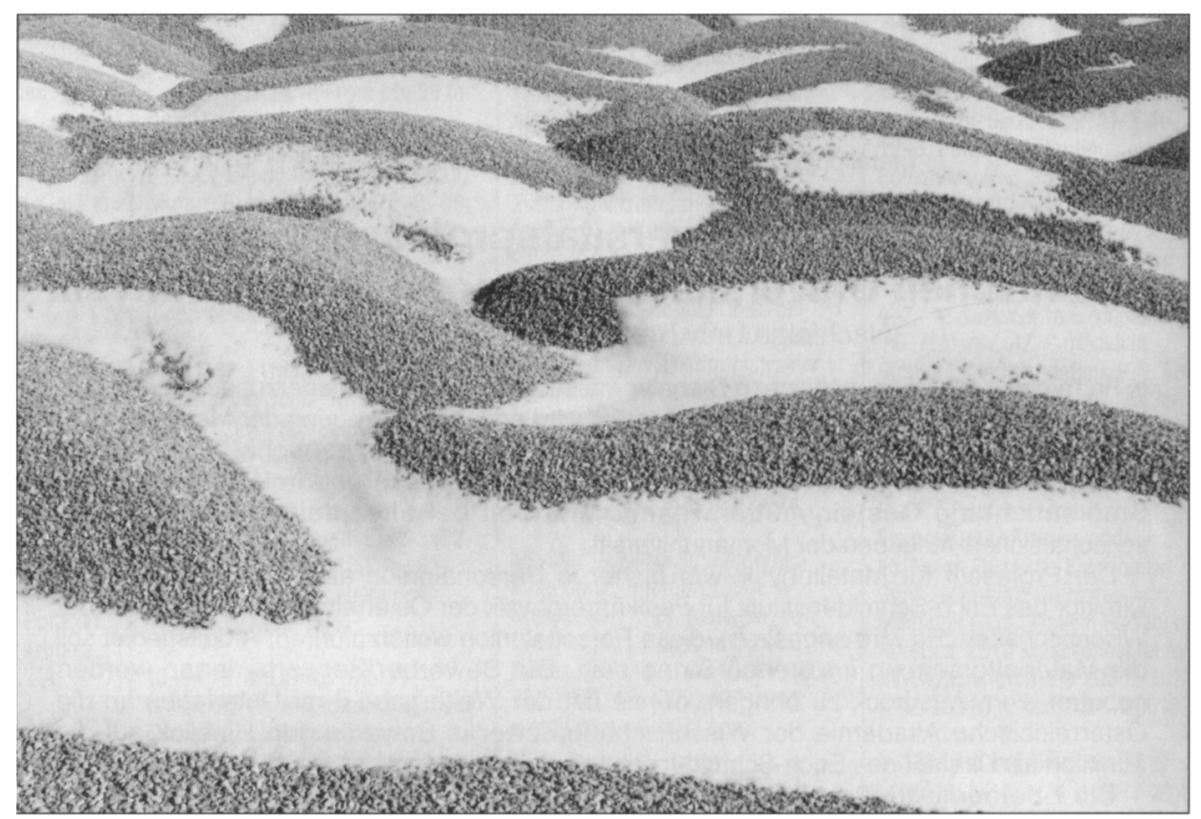

Snow on Aggregate Dunes at Barber's Corner (@ 1993 E.N. Kaufmann.)

how coarse the mesh? In parallel computing, how many processors parse the problem? In graphical displays, how may pixels make a picture on a screen and how many dots make a picture on a printed page?

To appreciate granularity in the abstract, we must equate the cells of a spreadsheet with the cells of a prison with the cells of our bodies with the cells of a cellphone. Language itself is granular of course. Our poet's gushing over the still pond's beauty will most certainly have been subdivided into stanzas and the stanzas into lines and the lines into words - well, you get the idea.

An interesting thing about grains is that their existence demands intergranular boundaries, interfaces, or at least spaces. Readers of MRS Bulletin are undoubtedly comfortable with the twist boundaries and tilt boundaries of microstructures. Surely the interstanzaic twists and tilts in meaning, or rhyme, or meter are equally impressive in poetic structure. Is the play the thing or is it the acts and scenes and the segues in between? The importance of the interfaces can not be overemphasized. Often, it's the interfaces in a composite material that determine its properties. In the column of sand, it is the intergranule contact that allows violation of simple hydrodynamics and erects configurational barriers to reorientation. Any observer of geopolitics understands this consequence of boundaries.

Although negative advertising runs against our grain, we must note that the beauty claimed by the proponents of the continuous and homogeneous is not their inherent property at all, but is mercifully conferred by granularity. If the mirror-like pond had no grains of the forest (trees) or of the sky (clouds) to reflect, how boring it would be. If the clear gemstone had no facets, no glints of light or hints of shape, how boring it would be. "If you can look into the seeds of time, and say which grain will grow and which will not, speak" ${ }^{6}$ or else how boring it would be.

E.N. KAUFMANN

1. For people, we find ways to reverse the connotations as well. Smoothness can be pushed toward the negative of slick disingenuous confidence man. Roughness can be mitigated and even be endearing if it is only found around the edges.

2. Comus [1634], I. 745.

3. Science (9 February 1996).

4. Physics News Update, No. 264, April 1, 1996

(American Institute of Physics).

5. William Blake, Poems from the Pickering Manuscript [c. 1805]. Auguries of Innocence, I. 1 . 6. William Shakespeare, Macbeth, Act: I, Scene: iii, line 58 . 